\title{
Vision, Aging and Quality of Life
}

\section{Impact of Low Vision on Well-Being in 10 European Countries}

\author{
S.M. Mojon-Azzi, A. Sousa-Poza, D.S. Mojon
}

Ophthalmologica 2008;222:205-212

Because of the growing life expectancy in developed countries and the exponential increase in vision loss with increasing age, a growing number of elderly persons will eventually suffer from visual impairment and blindness. Indeed, a tripling of vision loss can be expected with each additional decade of life after the age of 50 . Therefore it is important to know the impact of visual impairment on visual functioning, health and well-being. This study on 22,486 individuals analyses the influence of self-reported corrected general eyesight, corrected distance eyesight and corrected reading eyesight on several variables that describe emotional well-being, future hopes and concentration on daily activities. As this study is based on data from a large pool from ten European countries, the results do not only reflect the situation in one country. This study shows clearly that impaired vision negatively affects many aspects of the quality of life. With growing visual impairment respondents not only feel sad and depressed more often, they also loose enjoyment and hope and have more frequent suicidal feelings. This strong impact of low vision on well-being, together with its frequency and economy impact, makes visual impairment an important health issue. Even in developed countries, there is still great potential for improving both eyesight and quality of life with impaired vision. Early detection, prevention, rehabilitation, education and research would not only improve mental and physical health but would also reduce the economic impact of low vision.

\section{Prevention of Oxidative Stress to the Retina by Pyruvate}

Kavita R. Hegde, Shambhu D. Varma

Ophthalmologica 2008;222:194-198

Oxidative stress is considered to be a significant risk factor in the pathogenesis of many age-related eye diseases. Specificity of the involvement of oxygen in the retinal damage by oxygen has been proven in experimental animals by observations on structural as well as electrophysiological changes. The role of oxidative stress in retinal degeneration is also suggested by the partial protective effect of administering antioxidants and minerals in human populations. Although several antioxidants are available, it makes sense to use an antioxidant that can simultaneously provide metabolic support to the tissue. Pyruvate fulfills both these requirements. In isolated retinas the authors were able to show the effectiveness of pyruvate against oxidative, metabolic and structural damage to the retina. Fur- ther studies on the mechanism of the observed effects are in progress, especially in view of the non-toxicity of the compound administered topically or orally. A generalized suitability of the compound for in vivo use has been shown by adding it to the diet of diabetic animals for periods extending to 3-4 months without any sign of toxicity, with simultaneous inhibition of cataract formation.

\section{Posterior-Segment Surgeries with a Two-Port Modified Multiport Illumination System}

Hamdi Er, Penpegül Fırat

Ophthalmologica 2008;222:145-148

Different set-ups for the use of the multiport illumination system (MIS) are favoured by different surgeons. The authors consider the combination of an infusion line hooked up to one MIS port plus a second MIS port through which they insert 20-gauge (or smaller) straight instruments as most satisfying in their hands to manage a variety of vitreoretinal interventions (two-port pars plana vitrectomy). For more cumbersome cases with the need for bimanual techniques or the use of angled or curved instruments they open up an additional sclerotomy (no restrictions by port). Thus they have the full advantages of what they consider an excellent illumination with very low phototoxicity risks and full support for panoramic viewing in all of their cases. In over 60 retrospectively followed patients no severe intra- or postoperative complications - especially no endophthalmitis or retinal breaks/detachments - were noticed.

\section{Accessibility of Health Information on the Internet to the Visually Impaired User}

Marc Lüchtenberg, Claudia Kuhli-Hattenbach, Yesim Sinangin, Christian Ohrloff, Rainer Schalnus

Ophthalmologica 2008;222:187-193

In this paper the accessibility of health information on the Internet to the visually impaired user was studied. The amount of digitally available health information has dramatically increased. Unfortunately, chronically ill and old people, who in many cases suffer from conditions like coronary heart disease, chronic obstructive lung diseases and asthma, or diabetes, frequently suffer additionally from visual impairment. This makes it necessary to display not only information on eye diseases, but all kinds of health and medical information on the Internet, and to ensure barrier-free access to this information in a way that accommodates visually impaired users.

C. Ohrloff, Frankfurt a.M.

\section{KARGER}

Fax +41613061234 E-Mail karger@karger.ch www.karger.com
C) 2008 S. Karger AG, Basel

$0030-3755 / 08 / 2223-0144 \$ 24.50 / 0$

Accessible online at: www.karger.com/oph 